\title{
Microwaves Devulcanization of SBR Containing Carbon Black
}

\author{
Denise Hirayama, Carlos Henrique Scuracchio and Clodoaldo Saron ${ }^{*}$
}

\author{
Department of Materials Engineering, Engineering School of Lorena, University of São Paulo, LOM- \\ EEL/USP, Polo Urbo Industrial, Gleba Al-6, s/n, CEP: 12602-810, Lorena, SP, Brazil
}

\begin{abstract}
Polymer recycling has been the most suitable alternative for management of plastics waste that are responsible by serious environmental damages. However, the recycling of some polymer materials, such as vulcanized elastomers, is not a trivial process. The recycling of elastomers is a process more complex than the recycling of thermoplastic polymers because the elastomers cannot be remolded by simple heating after vulcanization. Methods for rubber devulcanization has been developed as an interesting alternative for recover flow properties of elastomers, allowing other molding cycle. The aim of this work was to evaluate the effect of the presence of carbon black on devulcanization of styrene-butadiene rubber (SBR) by microwaves and analyze properties of recycled material. The devulcanization by microwaves showed efficiency for rubber compositions with higher content of carbon black incorporated as well as the properties of recycled material showed satisfactory performance for reuse in other products. Microwaves devulcanization of SBR is an important alternative for reuse of rubber waste and decrease of the environmental problem generated with discard of these materials.
\end{abstract}

Keywords: Devulcanization, microwaves, rubber recycling.

\section{INTRODUCTION}

In last decades, the discard of rubber waste has caused serious environmental problems. These materials degrade very slowly in environmental conditions and their recycling is considered difficult [1, 2]. Rubber waste deposited in landfills occupies large areas and when deposited in other inappropriate places can cause principally air pollution by uncontrollable burning and several environmental problems as well as can breed insects and diseases [3]. The recycling of rubber is an alternative to control these problems. However, commercial rubbers have cross-links, formed by vulcanization process, between their main polymeric chains, impeding the remolding of material by heating.

The rubber devulcanization process promotes cross-links break and enable the waste rubber for reuse in new products. Thus, the reclamation of rubber contributes to decreasing of rubber wastes in environment as well as decreasing of consumption of virgin raw material and additives [4].

Nowadays, there are different devulcanization methods, including chemical, mechanical, thermomechanical, cryo-mechanical, microwaves, ultrasound and microbial [5-11]. Devulcanization by microwaves use electromagnetic radiation under frequency range of $300 \mathrm{MHz}$ to $300 \mathrm{GHz}$ [12]. Microwaves radiation can be absorbed by material through molecular interaction with

*Address correspondence to this author at the Department of Materials Engineering, Engineering School of Lorena, University of São Paulo, LOMEEL/USP, Polo Urbo Industrial, Gleba Al-6, s/n, CEP: 12602-810, Lorena, SP, Brazil; Tel: 55-12-159-9920; Fax: 55-12-3153-3006; E-mail: saron@usp.br the electromagnetic field and thus be converted to heat. Therefore, the use of microwaves energy allows the heat propagation inside of material, improving the efficiency of devulcanization at reduced processing times with energy savings [13].

The main microwaves heating mechanism is the dipole orientation. The electromagnetic field of microwaves produces a resonant orientation of molecular dipoles in material that are lead to partial alignment. The subsequent relaxation of dipoles to original conformation causes energy dissipation mainly as heat [14]. The interaction of material with electromagnetic radiation in the microwaves range not always results in fast heat liberation; it depends on dielectric loss property. Thus, the materials may be classified into three groups: conductors (which reflect microwaves), transparent (microwaves cross material without any losses) and absorbers (which absorb microwaves) [15]. The materials that absorb microwaves radiation are called dielectrics and the ability of a material to absorb energy is related to the loss tangent of the material. It depends on the relaxation times of the molecules in the materials, which depends on the nature of the functional groups and of the volume of the molecules [16]. SBR rubber as well as several others polymers have not intrinsic dipoles that allow microwaves absorption. However, filler incorporated to polymer such as carbon black can carry out this role.

Landini et al. (2007) carried out an important study about devulcanization and recovery of bromobutyl rubber (BIIR) using microwaves process [17]. The results showed that the microwaves process caused an 
Table 1: Composition of Ground Vulcanized Rubber

\begin{tabular}{|c|c|c|c|c|c|c|c|c|}
\hline \multirow{3}{*}{ Samples } & \multicolumn{8}{|c|}{ Composition } \\
\hline & \multicolumn{2}{|c|}{ SBR } & \multicolumn{2}{|c|}{ Carbon Black } & \multicolumn{2}{|c|}{ Accelerator } & \multicolumn{2}{|c|}{ Sulfur } \\
\hline & phr & wt $\%$ & phr & wt $\%$ & phr & wt $\%$ & phr & wt $\%$ \\
\hline SBR-0 & 100 & 96.81 & 0 & 0.00 & 1.3 & 1.26 & 2 & 1.94 \\
\hline SBR-40 & 100 & 69.78 & 40 & 27.91 & 1.3 & 0.91 & 2 & 1.40 \\
\hline SBR-60 & 100 & 61.24 & 60 & 36.74 & 1.3 & 0.80 & 2 & 1.22 \\
\hline SBR-100 & 100 & 49.19 & 100 & 49.19 & 1.3 & 0.64 & 2 & 0.98 \\
\hline
\end{tabular}

expressive effect in the BIIR recovery. Scuracchio et al. (2007) have studied the devulcanization process of ground tire rubber and verified that the rubber under microwaves treatment presented modification in chemical structure that depends of microwaves time exposure [18]. Thermogravimetry analysis for study of rubber devulcanization was firstly used by Kleps et al. (2000), which verified that thermogravimetry is a very useful method for investigation and control of the microwaves devulcanization process [19]. Other important works have been developed, which have been focused on the elucidation of physical and chemical mechanisms involved in the rubber devulcanization by microwaves as well as in potential of this method for rubber recycling [20-23].

The aim of this work was to evaluate the efficiency of the thermogravimetric analysis and the influence of carbon black on microwaves devulcanization of styrene-butadiene rubber (SBR), comparing with gel content analysis and evaluate possible properties of recycled material by dynamical mechanical thermal analysis (DMTA).

\section{EXPERIMENTAL}

\section{Materials}

Styrene-butadiene rubber SBR 1502 (SBR) and Carbon black N330 (CB) were received from SSP Agaprint Ltda (Pirituba, Brazil). Sulfur (S) and accelerator $\mathrm{N}$-cyclohexylbenzothiazole-2-sulfenamide (CBS) were supplied by Bann Química Ltda (São Paulo, Brazil).

Carbon black (CB) was incorporated into the SBR at $0,40,60$ and $100 \mathrm{phr}$, producing four different samples, while sulfur (S) and accelerator (CBS) were incorporated into all samples at 2 and $1.3 \mathrm{phr}$, respectively. The mixing of components was carried out in an open two roll mill Prenmar at room temperature during $15 \mathrm{~min}$. After homogenization the rubbers were vulcanized at $180^{\circ} \mathrm{C}$ and 150 bars in hydraulic molding press Tecnal TE-098-E2 for 2 min and ground in knifes mill and two rolls mill Prenmar to produce particles with 20 mesh of particle size. The identification of samples, according to their composition in weight percent, is presented in Table 1.

\section{Methods}

\section{Devulcanization by Microwaves}

The ground vulcanized rubber SBR (20 mesh) was devulcanized in a microwaves oven with a stirring system, as schematically showed in Figure 1.

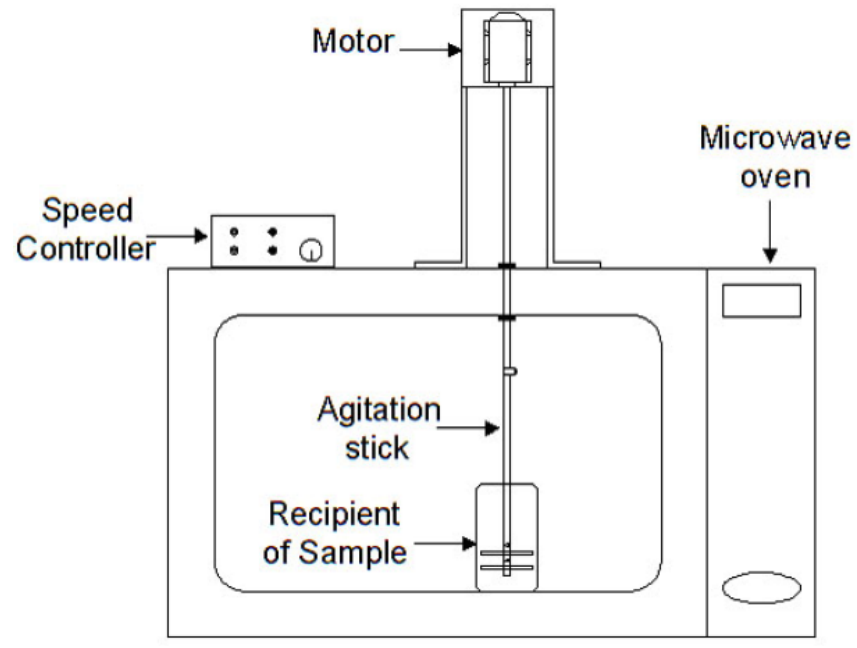

Figure 1: Schematic design of devulcanization bath system.

The power of the magnetron oven was set up to 700 $\mathrm{W}$ and $60 \mathrm{~g}$ of the ground rubber were put in a Becker of $250 \mathrm{~mL}$ with a stirring speed of $40 \mathrm{rpm}$ for $2 \mathrm{~min}$. The temperature after devulcanization was measured with a digital thermometer Salvterm type $\mathrm{K}$ couplet with an outward sensor. The sensor remained in the sample during test and the temperature immediately after microwaves treatment (2 min.) was recorded. The weight of rubber was measured before and after 
microwaves treatment. However, no significant weight variation was verified.

\section{Revulcanization}

In revulcanization process, equivalent amounts in weight of devulcanized rubber $(50 \%)$ and virgin rubber $(50 \%)$ were mixed together with the addictives CBS, sulfur and carbon black and molded under pressure, such as carried out in initial vulcanization process of virgin SBR, to produce a blend of virgin rubber with devulcanized rubber (RB). After revulcanization, the blends were cut out in samples with dimensions of 80 $\mathrm{mm} \times 25 \mathrm{~mm} \times 2.15 \mathrm{~mm}$ to evaluate their viscoelastic properties by dynamic mechanical thermal analysis (DMTA).

\section{Gel Content (GC)}

The gel content was determined by Soxhlet extraction using toluene as solvent. Approximately $5 \mathrm{~g}$ of each vulcanized and devulcanized ground rubber sample remain under Soxhlet extraction for $24 \mathrm{~h}$ until the soluble fraction had been extracted by solvent. Then, insoluble fraction was dried for $24 \mathrm{~h}$ at $60^{\circ} \mathrm{C}$ and their weight were measured for the gel content determination.

\section{Thermogravimetric Analysis (TGA)}

Thermogravimetric analysis were carried out in an equipment Shimadzu TGA 50 using $8 \mathrm{mg}$ of vulcanized and devulcanized ground rubber under $\mathrm{N}_{2}$ atmosphere at a heating rate of $10^{\circ} \mathrm{C}$ min, starting from room temperature up to $900^{\circ} \mathrm{C}$.

\section{Dynamic Mechanical Thermal Analysis (DMTA)}

DMTA of revulcanized blends (RB) and vulcanized SBR with different content of carbon black were carried out in a DMTA $V$ Rheometric coupled with cooling system of liquid nitrogen under a temperature range of $-145^{\circ} \mathrm{C}$ to $100^{\circ} \mathrm{C}$ under temperate rate of $2^{\circ} \mathrm{C} / \mathrm{min}$ and frequency of $1 \mathrm{~Hz}$.

\section{RESULTS AND DISCUSSION}

\section{Gel Content (GC)}

Free polymeric chains of SBR rubber before vulcanization are soluble in toluene, producing only one sol fraction. However, the reticulated network formed after vulcanization with sulfur is not soluble and only intumesces in presence of toluene, remaining in gel fraction after Soxhlet extraction. In the devulcanization process it is expected the breaking of sulfur cross-links in material and regeneration of free polymeric chains in SBR, decreasing gel content. Thus, gel content is an important parameter to evaluate the level of devulcanization after microwaves treatment. Table 2 shows the results of Soxhlet extraction for the vulcanized (VR) and devulcanized (DR) rubber with different amount of carbon black (CB) and the temperature of materials after devulcanization with microwaves.

It is noted in Table 2 that the gel content of vulcanized rubber is not $100 \%$. Thus, a portion of rubber remains free after vulcanization. It is expected because the vulcanization is a chemical reaction and it is not totally completed in the period that the material is submitted to the compression molding. The gel content decreases for vulcanized samples with higher amount of carbon black. It can occur due to steric effects produced by filler carbon black that dilutes the vulcanization agents and makes difficult the chemical reaction of vulcanization, reducing the inter-chain cross-links. On the other hand, the presence of carbon black determines the devulcanization of rubber since the variation between gel content of vulcanized and devulcanized only is significant for SBR with 60 and $100 \mathrm{phr}$ of carbon black, while the SBR with 0 and 40 phr of carbon black are not devulcanized by microwaves. This effect occurs because carbon black absorbs microwaves radiation and easily converts this energy to heat. Thus, in presence of microwaves radiation the carbon black promotes heating inside of

Table 2: Temperature of Material after Devulcanization and Gel Content for Vulcanized (VR) and Devulcanized (DR) SBR

\begin{tabular}{|c|c|c|c|c|c|}
\hline \multirow{2}{*}{ Samples } & \multirow{2}{*}{ CB $(\mathrm{phr})$} & Temperature $\left({ }^{\circ} \mathrm{C}\right)$ & \multicolumn{3}{|c|}{ Gel Content $(\%)$} \\
\cline { 4 - 6 } & & & VR & 90.53 & 0.01 \\
\hline \hline SBR-0 & 0 & 73 & 90.52 & 80.58 & 7.54 \\
\hline SBR-40 & 40 & 127 & 79.04 & 77.06 & -9.94 \\
\hline SBR-60 & 60 & 185 & 71.68 & 63.88 & -7.80 \\
\hline SBR-100 & 100 & 190 & & & \\
\hline
\end{tabular}


rubber, which is required to break cross-links of sulfur. The progressive increasing of temperature after devulcanization in SBR with higher carbon black content evidences this effect.

\section{Thermogravimetric Analyses (TGA)}

Thermogravimetric analyses were realized to evaluate the thermal behavior of vulcanized and devulcanized SBR in inert atmosphere with the purpose to establish parameters that differentiate the material after microwaves treatment.

Figures 2 and 3 compare the weight loss recorded by TGA curves of rubber vulcanized and devulcanized respectively with $0,40,60$ and 100 phr of carbon black. Note that both vulcanized and devulcanized rubber show two decomposition steps, the first starting around $200{ }^{\circ} \mathrm{C}$ followed by a second step around $400{ }^{\circ} \mathrm{C}$, showing that the samples have a weight fraction with lower thermal stability or the molecular decomposition occurs in two distinct processes. Considering the rubber composition and results of gel content it can be supposed that the first decomposition step may be related to decomposition of free polymeric chains, coinciding with sol fraction in gel content analysis. It is also observed that the presence of carbon black dislocate the second decomposition step for higher temperatures. It should be related to properties of stabilization of the carbon black. The weight residual formation at the end of thermogravimetric measures increases for SBR with higher amount of carbon black, reflecting the samples composition (Table 1). It shows that the first and second decomposition steps in TGA curves are referents to polymeric matrix, while residual formed is related to carbon black content in the rubber.

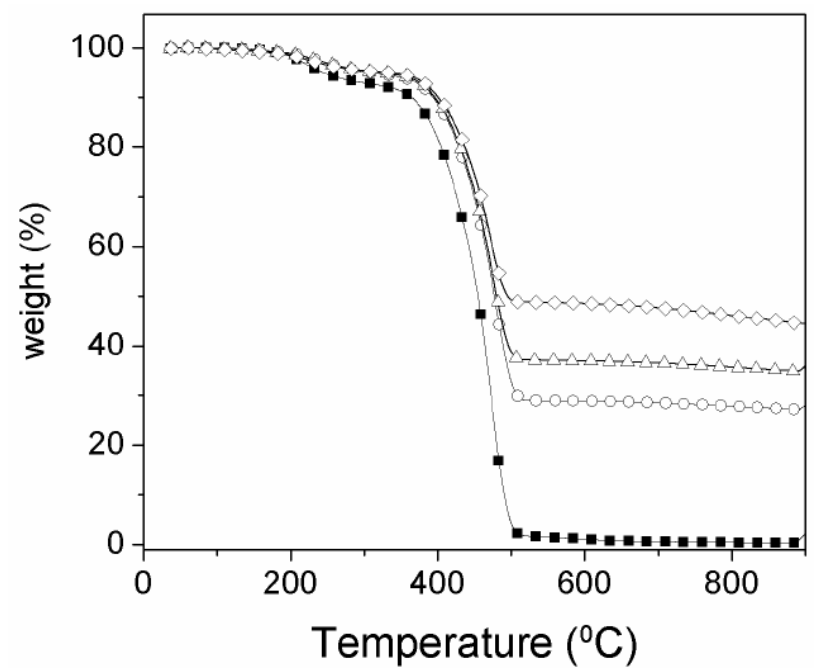

Figure 2: TGA curves of vulcanized rubber with 0 phr (-n-), $40 \mathrm{phr}\left(-{ }_{-}\right), 60 \mathrm{phr}\left(-\Delta^{-}\right)$and $100 \mathrm{phr}\left(-\diamond_{-}\right)$of carbon black.

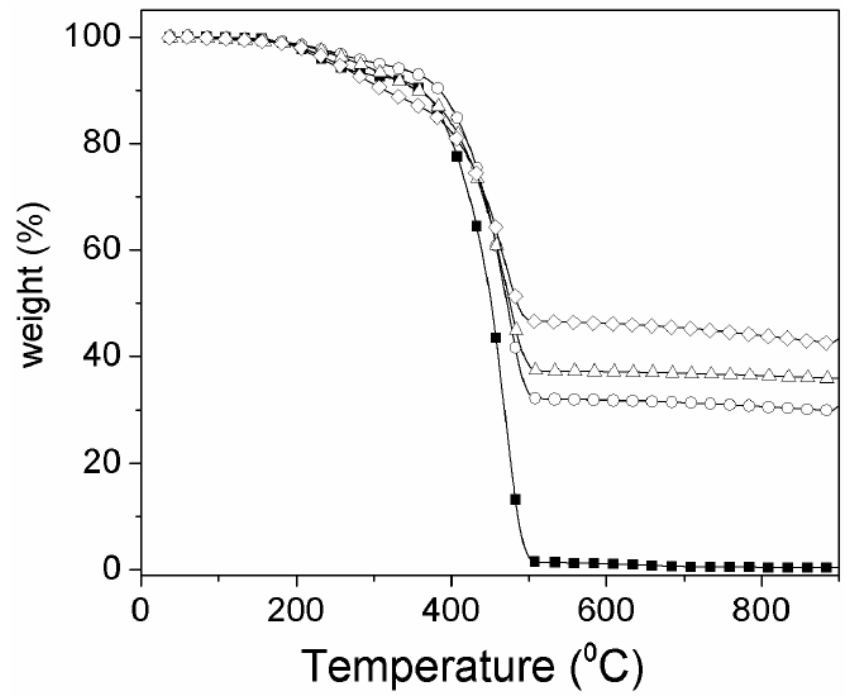

Figure 3: TGA curves of devulcanized rubber with $0 \mathrm{phr}$ $(--)$, $40 \mathrm{phr}(-\circ-), 60 \mathrm{phr}\left(-\Delta_{-}\right)$and $100 \mathrm{phr}\left(-\nabla_{-}\right)$of carbon black.

It shows that the first and second decomposition steps in TGA curves are referents to polymeric matrix, while residual formed is related to carbon black content in the rubber.

In devulcanized rubber (Figure 3 ) the weight loss in first decomposition step is more accentuated for SBR with 60 and $100 \mathrm{phr}$ of carbon black, evidencing that really the first decomposition step is related to free polymeric chains or sol fractions. This behavior can be better verified in the comparison between TGA and DTG curves of vulcanized and devulcanized SBR with 100 phr of carbon black (Figure 4).

It is noted in Figure 4 that in devulcanized SBR-100 occurs a higher weigh loss in temperature range (200 $430{ }^{\circ} \mathrm{C}$ ) between the first and second decomposition steps when compared to vulcanized SBR-100. This thermal change in devulcanized SBR-100 represents an increase of a material fraction with lesser thermal stability, which denotes that a portion of reticulated SBR (vulcanized) have been transformed in free polymeric chains (devulcanized) with variable molecular weight. In Table $\mathbf{3}$ are presented the results of TGA curves for vulcanized and devulcanized SBR with different amount of carbon black.

The effective devulcanization degree can be calculated (Table 3 ) by difference between weight loss of devulcanized and vulcanized in first decomposition step of TGA (DR-VR). It is observed that devulcanization in SBR-0 and SBR-40 is not significant. However, the DR-VR values for SBR-60 and SBR-100 were approximately 3 and $7 \%$, respectively, which are 


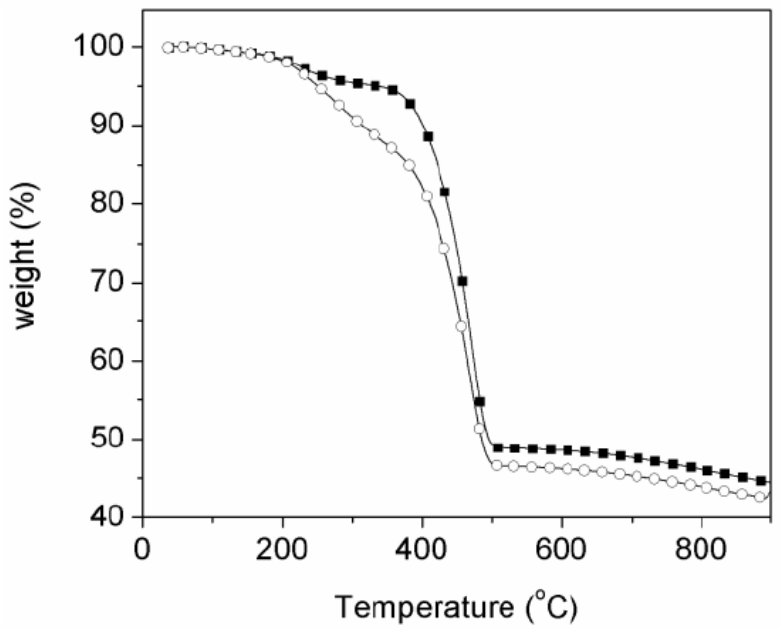

a

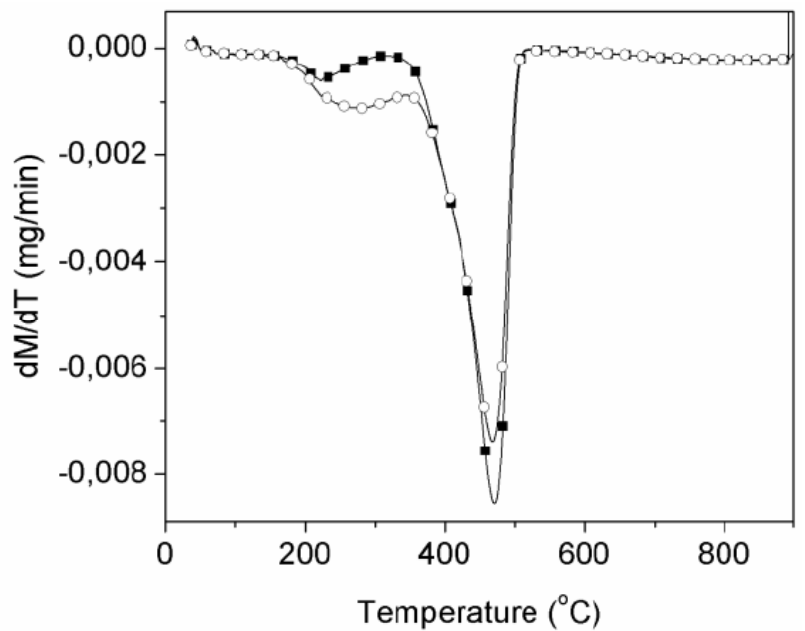

b

Figure 4: Thermogravimetric analyses of vulcanized rubber (---) and devulcanized rubber (-०-) with 100 phr of carbon black: a) TGA curves; b) DTG curves.

similar to those found by gel content analysis. These results show that TGA can be used as analytic technical for devulcanization quantification in SBR and possibly for others rubbers too. A comparison between devulcanization degree calculated for thermogravimetric and gel content analysis relative to only polymeric matrix is presented in Table 4.

Both TGA and GC methods showed that microwaves treatment was effective only for devulcanization of SBR with more $60 \mathrm{phr}$ of carbon black. Differences in absolute values between TGA and GC methods may be caused by factors that affect the precision of each technical. In GC analyses, the sol fraction is removed of reticulated portion by Soxhlet extraction. Extraction methods are intrinsically imprecise due to error propagation during all process such as retention of free chains in aggregates of filler or in reticulations, loss of material in filter or in others parts of extraction system and problems with solvent removal or end weight determination. Thus, GC method did not allow accurately to determinate the devulcanization degree for SBR with more $60 \mathrm{phr}$ of carbon black. On the other hand, TGA method allows decomposition of less thermally stable molecules inside of material. A tendency of increase in devulcanization

Table 3: Thermogravimetric Data for Vulcanized and Devulcanized SBR with Different Amount of Carbon Black

\begin{tabular}{|c|c|c|c|c|c|}
\hline Samples & CB (phr) & $\operatorname{TR}^{\mathrm{a}}\left({ }^{\circ} \mathrm{C}\right)$ & $\mathrm{VR}^{\mathrm{a}}(\%)$ & $\mathrm{DR}^{\mathrm{b}}(\%)$ & DR-VR (\%) \\
\hline \multirow{3}{*}{ SBR-0 } & \multirow{3}{*}{0} & 100 to 400 & 7.41 & 7.07 & -0.34 \\
\hline & & 400 to 600 & 90.61 & 90.91 & +0.30 \\
\hline & & Residual weight (900) & 1.74 & 1.42 & -0.32 \\
\hline \multirow{3}{*}{ SBR-40 } & \multirow{3}{*}{40} & 100 to 400 & 4.71 & 4.59 & -0.12 \\
\hline & & 400 to 600 & 65.44 & 62.21 & -3.23 \\
\hline & & Residual weight (900) & 29.00 & 31.98 & +2.98 \\
\hline \multirow{3}{*}{ SBR-60 } & \multirow{3}{*}{60} & 100 to 400 & 4.26 & 7.12 & +2.86 \\
\hline & & 400 to 600 & 57.49 & 53.51 & -3.98 \\
\hline & & Residual weight (900) & 37.21 & 37.26 & +0.05 \\
\hline \multirow{3}{*}{ SBR-100 } & \multirow{3}{*}{100} & 100 to 400 & 3.96 & 11.25 & +7.29 \\
\hline & & 400 to 600 & 46.15 & 40.98 & -5.17 \\
\hline & & Residual weight (900) & 48.84 & 46.54 & -2.30 \\
\hline
\end{tabular}

${ }^{\mathrm{a}}$ Temperature range for determined decomposition step.

${ }^{b}$ Weight lost or residual for vulcanize SBR.

'Weight lost or residual for devulcanize SBR. 
degree of SBR rubber can be verified with the increase of carbon black content in material, showing that TGA method is more precise than GC method for this determination. However, TGA method is not totally free of factors that can affect the measure precision. Garcia et al. (2015) describe that the barrier effect caused by carbon black filler can difficult the exit of volatile compounds produced inside material during thermal decomposition, affecting of registered values of weight loss [20].

Table 4: Devulcanization Degree for Gel Content (GC) and Termogravimetric Analysis (TG)

\begin{tabular}{|c|c|c|}
\hline \multirow{2}{*}{$\mathbf{C B}^{*}(\mathbf{p h r})$} & \multicolumn{2}{|c|}{ Devulcanization Degree (\%) } \\
\cline { 2 - 3 } & GC & TG \\
\hline \hline 0 & 0 & 0 \\
\hline 40 & 0 & 0 \\
\hline 60 & 10 & 3 \\
\hline 100 & 8 & 7 \\
\hline
\end{tabular}

\section{Dynamic Mechanical Thermal Analysis (DMTA)}

DMTA is a sensible method to evaluate relaxations in polymeric materials, which occur as a function of time or temperature, allowing the study of viscoelastic properties of the polymers. Figure 5 presents the comparison between storage modulus ( $\left.E^{\prime}\right)$ of vulcanized rubber $(\mathrm{VR})$ with variable content of carbon black.

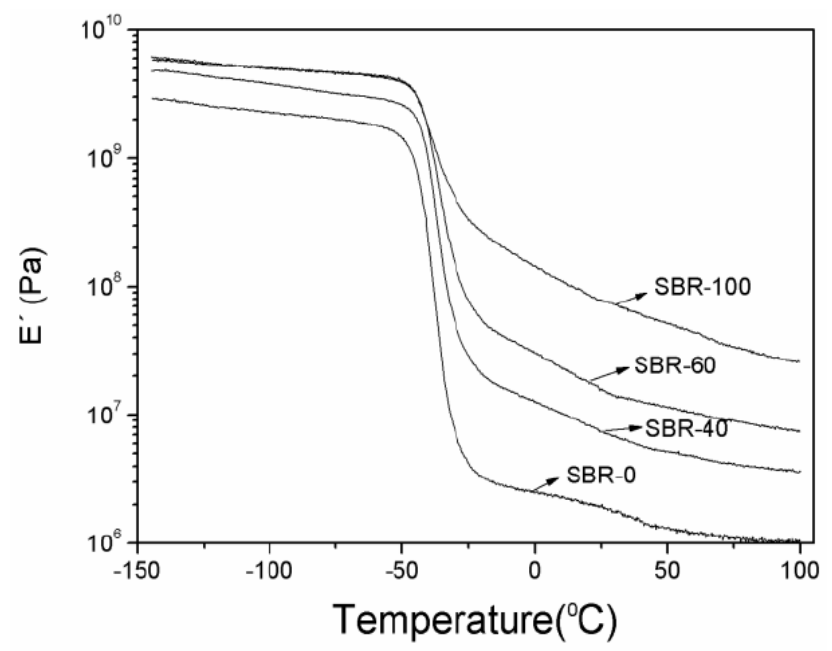

Figure 5: DMTA E' curves of vulcanized rubber with variable content of carbon black.

Vulcanized SBR presents typical values of storage modulus for polymers, above $10^{9} \mathrm{~Pa}$ at low temperature, which decrease to the rubbery level after glass transition around $-40{ }^{\circ} \mathrm{C}$. The incorporation of carbon black to the SBR leads to a progressive increase of $E^{\prime}$, mainly in rubbery level after glass transition. Thus, carbon black modifies the rubber for more rigid materials. The same behavior is also verified in the $\mathrm{E}^{\prime}$ curves of the revulcanized blends (RB), containing $50 \%$ of virgin rubber and $50 \%$ devulcanized SBR (Figure 6). The storage modulus of revulcanized SBR shows that the material has viscoelastic behavior similar to the vulcanized virgin SBR.

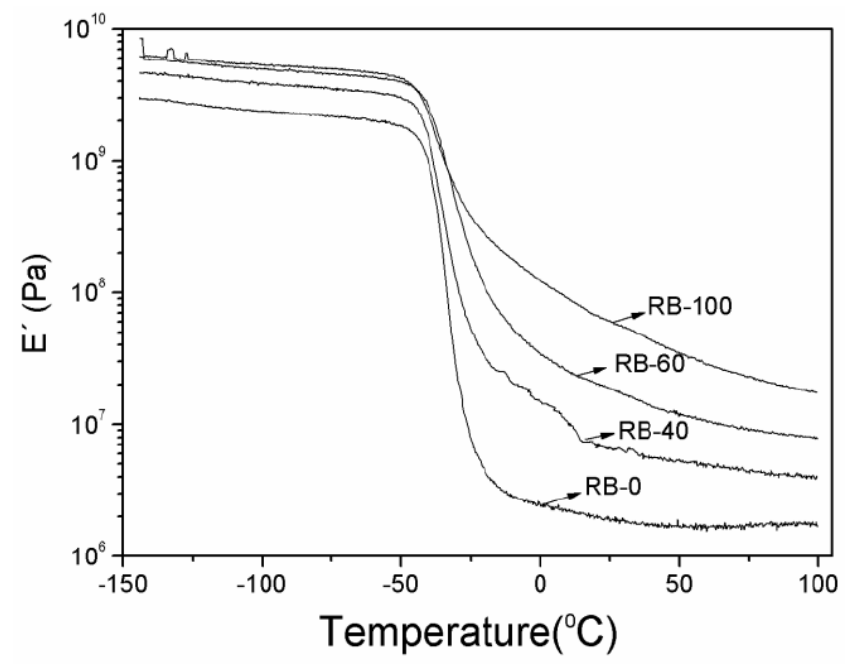

Figure 6. DMTA E' curves of revulcanized blend $(50 \%$ of virgin SBR and $50 \%$ of devulcanized SBR) with variable content of carbon black.

The effects of the rubber devulcanization on the storage modulus can be observed in full detail in Figure 7.

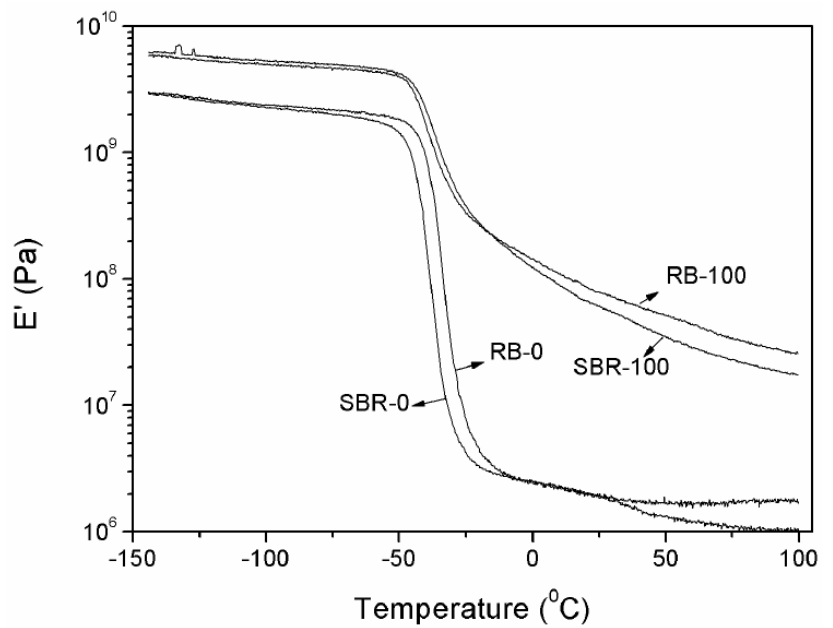

Figure 7: Comparison between DMTA $E^{\prime}$ curves for vulcanized rubber and revulcanized blends with 0 and 100 phr of carbon black.

The blend without carbon black (RB-0) presents storage modulus $\mathrm{E}^{\prime}$ and consequent higher rigidity than 
virgin vulcanized rubber (SBR-0). However, the curves of SBR containing $100 \mathrm{phr}$ of carbon black (SBR-100) and respective blend (RB-100) are practically equals until zero ${ }^{\circ} \mathrm{C}$. Above zero ${ }^{\circ} \mathrm{C}$ the blend RB-100 presents lower values of storage modulus than virgin vulcanized SBR-100. Consequently, their rigidity is lower too, while the elasticity is higher. This result shows that the devulcanized fraction of SBR-100 obtained by microwaves treatment is able to change viscoelastic properties to the recyclable rubber that allow a possible mixture with virgin rubber, maintaining the performance of material for determined applications.

\section{CONCLUSIONS}

Vulcanization and devulcanization of SBR rubber by microwaves treatment are processes significantly influenced by content of carbon black filler in material. Vulcanization percentage of SBR decrease as content of carbon black is increased in material, while devulcanization is more effective for samples with higher content of carbon black and only was verified in SBR containing above $60 \mathrm{phr}$ of filler. The increase in temperature of devulcanization as a function of carbon black content in SBR shows that the filler is the responsible by conversion of microwaves radiation to thermal energy inside of material, which promote the SBR devulcanization.

Thermogravimetry shows that can also be used to evaluate the devulcanization degree in SBR rubber after microwaves treatment. The speed and easiness in procedures for analysis are some advantages of thermogravimetry when compared to gel content analysis.

The incorporation of devulcanized SBR with low content of carbon black to virgin SBR with subsequent revulcanization, generating a revulcanized blend, lead to a more rigid material when compared to virgin vulcanized SBR. However, the revulcanization of blend with high content of carbon black, lead to a material with storage modulus $\left(E^{\prime}\right)$ similar to the correspondent virgin vulcanized SBR. Thus, the microwaves devulcanization demonstrates potential to be used as a method for mechanical recycling of vulcanized elastomers. However, it is indispensable the improvement of devulcanization system with the purpose of increase the devulcanized fraction in the rubber. The combination of microwaves with other devulcanization systems can be an alternative to obtain higher performance of the devulcanization process.

\section{ACKNOWLEDGEMENTS}

The authors would like to thank the SSP Agaprint and Bann Química for the supply the materials and reagents and CAPES and FAPESP (Proc. 2007/076769) by finance support.

\section{REFERENCES}

[1] De D, Das A, Dey B. Debnath, SC, Roy BC. Reclaiming of ground rubber tire (GRT) by a novel reclaiming agent. Eur Polym J 2006; 42: 917-27.

http://dx.doi.org/10.1016/j.eurpolymj.2005.10.003

[2] Colom X, Canavate J, Carrilo F, Sunol JJ. Effect of the particle size and acid pretreatments on compatibility and properties of recycled HDPE plastic bottles filled with ground tyre powder. J Appl Polym Sci 2009; 15: 1882-90. http://dx.doi.org/10.1002/app.29611

[3] Mui ELK, Ko DCK, McKay G. Production of active carbons from waste tyres - a review. Carbon 2004; 42: 2789-805. http://dx.doi.org/10.1016/j.carbon.2004.06.023

[4] Garforth AA, Ali S, Hernandez-Martinez J, Akah A. Feedstock recycling of polymer wastes. Curr Opin Sol State Mater Sci 2004; 8: 419-25.

http://dx.doi.org/10.1016/j.cossms.2005.04.003

[5] Adhikari B, De D, Maiti S. Reclamation and recycling of waste rubber. Prog Polym Sci 2000; 25: 909-48. http://dx.doi.org/10.1016/S0079-6700(00)00020-4

[6] Rajan VV, Dierkes WK, Joseph R, Noordermeer JWN. Science and technology of rubber reclamation with special attention to NR-based waste latex products. Prog Polym Sci 2006; 31: 811-34. http://dx.doi.org/10.1016/j.progpolymsci.2006.08.003

[7] Isayev Al, Sujan B. Nonisothermal vulcanization of devulcanized GRT with reversion type behavior. J Elastomers Plast 2006; 38: 291-318. http://dx.doi.org/10.1177/0095244306067424

[8] Wang X, Shi C, Zhang L, Zhang Y. Effects of shear stress and subcritical water on devulcanization of styrenebutadiene rubber based ground tire rubber in a twin-screw extruder. J Appl Polym Sci 2013; 130: 1845-54. http://dx.doi.org/10.1002/app.39253

[9] Paulo GD, Hirayama D, Saron C. Microwave devulcanization of waste rubber with inorganic salts and nitric acid. Adv Mater Res 2012; 418-420: 1072-5.

http://dx.doi.org/10.4028/www.scientific.net/AMR.418420.1072

[10] Hirayama D, Saron C. Chemical modifications in styrenebutadiene rubber after microwave devulcanization. Ind Eng Chem Res 2012; 51: 3975-80. http://dx.doi.org/10.1021/ie202077g

[11] Jiang G, Zhao S, Li W, et al. Microbial desulfurization of SBR ground rubber by Sphingomonas $\mathrm{sp}$. and its utilization as filler in NR compounds. Polym Adv Technol 2011; 22: 234451.

http://dx.doi.org/10.1002/pat.1769

[12] Lidstrom P, Tierney J, Wathey B, Westman J. Microwaveassisted organic synthesis: a review. Tetrahedron 2001; 57 : 9225-83.

http://dx.doi.org/10.1016/S0040-4020(01)00906-1

[13] Siores E, Dorego DJ. Microwave applications in materials joining. Mater Process Technol 1995; 48: 619-25. http://dx.doi.org/10.1016/0924-0136(94)01701-2

[14] Thostenson ET, Chou TW. Microwave processing: fundamentals and applications. Composites A-Appl Sci Manuf 1999; 30: 1055-71. http://dx.doi.org/10.1016/S1359-835X(99)00020-2 
[15] Al-Harahsheh M, Kingman SW. Microwave-assisted leaching - a review. Hydrometallurgy 2004; 73: 189-203. http://dx.doi.org/10.1016/j.hydromet.2003.10.006

[16] Jones DA, Lelyveld TP, Mavrofidis SD, Kingman SW, Miles $\mathrm{N}$. Microwave heating applications in environmental engineering - a review. J Resourc Conserv Recycling 2002; 34: 75-90. http://dx.doi.org/10.1016/S0921-3449(01)00088-X

[17] Landini L, Araujo SG, Lugao AB, Wiebeck H. Preliminary analysis to BIIR recovery using the microwave process. Eur Polym J 2007; 43: 2725-31. http://dx.doi.org/10.1016/j.eurpolymj.2007.03.017

[18] Scuracchio CH, Waki DA, Silva MLC. Thermal analysis of ground tire rubber devulcanized by microwaves. J Thermal Anal Calorim 2007; 87: 893-7. http://dx.doi.org/10.1007/s10973-005-7419-8

[19] Kleps T, Piaskiewicz M, Parasiewicz W. The use of thermogravimetry in the study of rubber devulcanization. J Thermal Anal Calorim 2000; 60: 271-7. http://dx.doi.org/10.1023/A:1010134315762
[20] Garcia PS, Souza FDB, Cruz SA, Scuracchio $\mathrm{CH}$. Devulcanization of ground tire rubber: Physical and chemical changes after different microwave exposure times. Express Polym Lett 2015; 9: 1015-26.

http://dx.doi.org/10.3144/expresspolymlett.2015.91

[21] Molanorouzi M, Mohaved SO. Reclaiming waste tire rubber by an irradiation technique. Polym Degrad Stab 2016; 128 : 115-25. http://dx.doi.org/10.1016/j.polymdegradstab.2016.03.009

[22] Colom X, Faliq A, Formela K, Canavate J. FTIR spectroscopic and thermogravimetric characterization of ground tyre rubber devulcanized by microwave treatment. Polym Testing 2016; 52: 200-8. http://dx.doi.org/10.1016/j.polymertesting.2016.04.020

[23] Liu J, Liu P, Zhang X, Lu P, Zhang X, Zhang M. Fabrication of magnetic rubber composites by recycling waste rubber powders via a microwave-assisted in situ surface modification and semi-devulcanization process. Chem Eng J 2016; 295: 73-9. http://dx.doi.org/10.1016/j.cej.2016.03.025

\section{DOI: http://dx.doi.org/10.6000/1929-5995.2016.05.02.1}

(c) 2016 Hirayama et al.; Licensee Lifescience Global.

This is an open access article licensed under the terms of the Creative Commons Attribution Non-Commercial License (http://creativecommons.org/licenses/by-nc/3.0/) which permits unrestricted, non-commercial use, distribution and reproduction in any medium, provided the work is properly cited. 